\title{
Desafios da Pesquisa em Aprendizagem Organizacional
}

\author{
Challenges of Organizational Learning Research
}

\author{
Ronaldo Alves Nogueira ${ }^{1}$ \\ Catarina Cecília Odelius ${ }^{2}$
}

\begin{abstract}
Resumo
Esta revisão de literatura sobre aprendizagem organizacional aponta cinco principais desafios enfrentados por pesquisadores desse campo. Os desafios identificados foram de caráter teórico, conceitual e metodológico e merecem atenção especial no momento de planejamento de projetos de pesquisa nessa área. A primeira constatação do levantamento bibliográfico é que inexiste uma teoria da aprendizagem organizacional e, portanto, os pesquisadores enfrentam o desafio de erigir teoria relativa a esse fenômeno complexo e multifacetado. Já o segundo desafio refere-se à análise multinível de um processo que ocorre em nível individual e transcende o grupo, a organização e outras organizações, exigindo um modelo de análise adequado. O tema vem sendo estudado por diversas disciplinas sob perspectivas distintas, representando a terceira constatação da pesquisa e o desafio de construir pontes interdisciplinares para o desenvolvimento de uma teoria abrangente e útil em diversos campos da ciência. Esse desafio se torna ainda mais complexo diante da constatação da multiplicidade de conceitos e construtos de pesquisa relacionados diretamente com o mesmo processo de geração e operação de conhecimento para adaptação e performance organizacional. Por fim, o quinto desafio refere-se às metodologias de pesquisa sobre aprendizagem organizacional, com possibilidades pouco exploradas e uma hegemonia dos instrumentos de percepção individual.
\end{abstract}

Palavras-chave: Aprendizagem organizacional. Modelos de aprendizagem. Processo multinível.

\begin{abstract}
This literature review on organizational learning points out five main challenges faced by researchers from this field. The challenges identified had a theoretical, conceptual, and methodological nature and they deserve a special attention at the time of planning research projects in this area. The first finding of the bibliographical survey is that there is not a theory of organizational learning and, therefore, researchers face the challenge of building theory related to this complex and multifaceted phenomenon. In turn, the second challenge refers to multilevel analysis of a process that takes place at the individual level and goes beyond the group, the organization, and other organizations, requiring a suitable analytical model. The theme has been studied by several disciplines from different perspectives, representing the third research finding and the challenge of building interdisciplinary bridges to develop a comprehensive and useful theory in various fields of science. This challenge becomes even more complex given the verification of the multiplicity of research
\end{abstract}

Artigo submetido em 4 de novembro de 2013 e aceito para publicação em 30 de setembro de 2014

DOI: http://dx.doi.org/10.1590/1679-395112602

1 Doutorando em Administração na Universidade de Brasília (UnB); Mestre em Administração e Políticas Públicas pelo Instituto Universitário de Lisboa; Especialista em Direito Público pela Pontifícia Universidade Católica de Minas Gerais (PUC-Minas); Graduado em Administração Pública pela Fundação João Pinheiro (FJP); Analista de Finanças e Controle da Controladoria Geral da União. Endereço: UnB/PPGA, Campus Universitário Darcy Ribeiro - Prédio da FACE, CEP 70910-900, Brasília-DF, Brasil. E-mail: ronaldoppga@unb.br

2 Professora Associada da Universidade de Brasília (UnB); Doutora em Psicologia pela UnB. Mestre em Psicologia da Educação pela Pontifícia Universidade Católica de São Paulo (PUC-SP); Graduada em Administração de Empresas pelas Faculdades Metropolitanas Unidas (FMU). Endereço: UnB/PPGA, Campus Universitário Darcy Ribeiro - Prédio da FACE, CEP 70910-900, Brasília-DF, Brasil. E-mail: codelius@unb.br 
concepts and constructs directly related to the same processes of generating and operating knowledge for organizational adaptation and performance. Finally, the fifth challenge refers to research methodologies on organizational learning, with barely explored possibilities and hegemony of instruments of individual perception.

Keywords: Organizational learning. Learning models. Multilevel process.

\section{Introdução}

Desde 1990, o comércio mundial duplica-se aproximadamente a cada 6 anos. A cada 2 anos dobra a capacidade de armazenagem dos chips, mantendo os custos de produção. Portanto, o ritmo das mudanças é exponencial e não linear, o que gera dificuldade para a percepção humana, que é fundamentalmente linear. $\mathrm{O}$ custo da tecnologia vem reduzindo exponencialmente, embora o crescimento vertiginoso do volume de informações e a necessidade de processamento continuem a implicar custos crescentes. A comunicação entre indivíduos e organizações sofreu incremento em termos de velocidade e volume de informações. A comunicação ocorre em tempo real, reduzindo distâncias e possibilitando o compartilhamento de opinião em velocidade praticamente instantânea.

Esse é o cenário em que as organizações atuam nessas duas últimas décadas, designadas era do conhecimento (CASTELLS, 2011). A evolução econômica, a globalização, as novas tecnologias da informação e comunicação, a explosão do acesso e da produção de conhecimento por meio da internet são fenômenos que nos trouxeram à chamada era do conhecimento ou economia do conhecimento (CASTELLS, 2011). Nesse ambiente competitivo, com rápidas mudanças tecnológicas, as organizações buscam conhecimento, tecnologias e condições de adaptação e sobrevivência (ARGOTE, MCEVILY e REAGANS, 2003). Nesse ambiente, aprender, reaprender, desaprender, adaptar, inovar e mudar tornaram-se atividades rotineiras no dia a dia organizacional. Aprendizagem, análise, imitação, renovação e mudança tecnológica são os principais componentes de qualquer esforço para melhorar o desempenho organizacional e fortalecer a vantagem competitiva (MARCH, 1991). Por isso, tem sido crescente a preocupação prática e acadêmica com o fenômeno da aprendizagem organizacional (DODGSON, 1993; ROUSSEAU, 1997; GARVIN, 2000; CHIVA e ALEGRE, 2005; ANTONELLO e GODOY, 2011; ARGOTE, 2013; MOZZATO e BITENCOURT, 2013).

O interesse no campo da aprendizagem organizacional e da gestão do conhecimento entre os pesquisadores de estudos organizacionais aumentou consideravelmente nas últimas décadas (ARGOTE, 2005; FRIEDMAN, LIPSHITZ e POPPER, 2005) e o interesse pelo tema tem crescido de forma rápida (BORGESANDRADE, ABBAD e MOURÃO, 2006), resultando no desenvolvimento de diversas posições teóricas que incluem, entre outras, as obras clássicas da teoria da firma de Cyert e March (1963) e o desenvolvimento do conceito de capacidades dinâmicas (TEECE, PISANO e SHUEN, 1997). Cyert e March (1963), ao propor uma teoria comportamental da firma e abordar o modo como as organizações tomam decisões, desenvolvem 4 subteorias relativas a: metas, expectativas, escolhas e controle organizacionais; e, ainda, estabelecem 4 conceitos relacionais, entre os quais está a aprendizagem organizacional. Para os autores, a firma é considerada um sistema racional adaptativo no qual ocorre a aprendizagem pela experiência, principalmente por meio de processos adaptativos de metas, regras e procedimentos de pesquisa. Nessa visão atual, não se questiona a capacidade das organizações aprenderem nem que a aprendizagem se tornou vital para a sobrevivência de longo prazo (FRIEDMAN, LIPSHITZ e POPPER, 2005). As crescentes pressões competitivas alimentam o interesse na aprendizagem organizacional como um dos principais determinantes do desempenho organizacional sustentável, o que sugere que, para sobreviver e prosperar, as empresas terão de aprender em ritmo cada vez maior (ROUSSEAU, 1997).

Neste ensaio, o propósito principal é apontar e discutir os desafios das pesquisas nesse campo, à luz do referencial teórico de aprendizagem organizacional e das teorias organizacionais como um todo. O texto contribui para o debate acadêmico e para a proposição de projetos de pesquisa que visem investigar os 
fenômenos multidimensionais que envolvem aprendizagem no âmbito das organizações. Considerando que as pesquisas devem explorar as fronteiras do conhecimento, torna-se imperioso revisar o conhecimento acumulado nesse campo, para construção adequada de metodologia e quadros de análise. Nesse sentido, apontamos os quadros de análise teórica propostos por pesquisadores para aprendizagem organizacional.

Partimos da constatação de Crossan, Maurer e White (2011) de que o desafio de desenvolver uma teoria de aprendizagem organizacional amplamente aceita permanece mesmo após dez anos de muitos trabalhos sobre o tema. Portanto, o desafio número um para pesquisas do campo é a inexistência de uma "teoria da aprendizagem organizacional", capaz de servir de base para novas pesquisas, com pressupostos, premissas e hipóteses contendo ideias necessariamente falseáveis, testáveis diante das evidências (CROSSAN, LANE e WHITE, 1999; RUSS-EFT, 2004; CROSSAN, MAURER e WHITE, 2011). De fato, esse é um desafio de todo o campo organizacional. Para Davis (2010), a teoria das organizações acumulou um arsenal impressionante de construtos e mecanismos teóricos em vários níveis de análise ao longo de meio século e registrou dezenas de regularidades. No entanto, a natureza do objeto de pesquisa torna improvável que o campo produza teorias gerais e precisas. As evidências mostram que alguns poucos paradigmas do final dos anos 1970 ainda exercem uma influência predominante na teoria organizacional (DAVIS, 2010). As pesquisas publicadas continuam a se referenciar nesses paradigmas e os progressos teóricos tendem a tomar a forma de qualificações ou modificações modestas dentro desses paradigmas.

A aprendizagem organizacional é um tópico essencialmente interdisciplinar (ARGOTE, MCEVILY, e REAGANS, 2003). Diversos campos de estudo contribuem e desenvolvem pesquisas de aprendizagem organizacional, incluindo a psicologia, sociologia, economia, sistemas de informação, gestão estratégica, engenharia, teoria organizacional e comportamento organizacional. Essa interdisciplinaridade apresenta-se como uma riqueza na diversidade de perspectivas de análise, mas, ao mesmo tempo, um desafio no sentido de construir pontes entre os diferentes campos do conhecimento. Assim, um segundo desafio para a pesquisa desse tema é inter-relacionar o conhecimento sobre aprendizagem organizacional desenvolvido em diversas disciplinas.

Nesse ambiente interdisciplinar do fenômeno da aprendizagem organizacional, outro desafio encontrado é de caráter conceitual. Uma articulação de conceitos se mostra necessária para prevenir o risco de estudar construtos iguais com designações distintas, levando a relações espúrias, correlações altíssimas entre duas variáveis que medem a mesma coisa ou, ainda, disputas acadêmicas pelo "título" do mesmo fenômeno estudado.

Outro desafio refere-se às metodologias de pesquisa nesse campo. Decorrente e relacionado ao desafio conceitual, o desafio metodológico para investigar o fenômeno da aprendizagem organizacional também decorre de seu caráter multinível, havendo necessidade de desenhar ferramental de pesquisa que separe adequadamente os níveis de análise e que supere o uso de instrumentos de medição pautados em percepção para inferir resultados e relações entre fenômenos.

Em termos de metodologia, a pesquisa para o desenvolvimento deste ensaio seguiu heurística básica bem estabelecida: a) pesquisa bibliográfica nos principais periódicos e instrumentos de busca acadêmica; b) revisão bibliográfica relacionando em planilha eletrônica os trabalhos lidos, com identificação de periódico, ano, autores, título, resumo e principais contribuições; c) verificação de intensidades de citação como proxy da influência teórica dos autores; e d) compilação da pesquisa, comparando e contrastando as premissas, proposições, quadros de análise e metodologias utilizadas. A leitura do conjunto das obras torna o processo pessoal e idiossincrático, ainda que influenciado pela participação em grupo de pesquisa nesse campo e pelo debate em torno do tema.

Assim, a partir de um resgate de alguns dos principais autores que influenciaram o campo, o trabalho se estrutura na descrição dos desafios para a pesquisa do tema, apontando dificuldades e possibilidades para a proposição de projetos de pesquisa. Há que considerar que os desafios identificados são de caráter teóricoconceitual e metodológico e, em alguma medida, eles se encontram entrelaçados. 


\section{Desafio Teórico}

A literatura de aprendizagem organizacional é ampla, embora seja mais embasada em trabalhos teóricos que empíricos. Em geral, as quatro fontes de referência mais frequentes e influentes para os estudos de aprendizagem organizacional são Argyris e Schön (1978), Daft e Weick (1984), Fiol e Lyles (1985) e Levitt e March (1988). Embora não representem todas as teorias de aprendizagem organizacional, essas quatro fontes, entre as mais citadas, sintetizam as perspectivas mais influentes dos trabalhos contemporâneos nesse campo e merecem destaque.

Argyris e Schön $(1978 ; 1996)$ abordam a aprendizagem organizacional como processo de detecção de falhas, seguido de análise para correção de rumo. Na linguagem organizacional, o erro deve ser entendido como a diferença entre o planejado realizar e o que foi efetivamente feito, buscando racionalizar e facilitar o processo produtivo. Entre os conceitos mais relevantes propostos por Argyris e Schön $(1978 ; 1996)$ incluem teorias da ação adotada, teorias em uso e aprendizagem de ciclo simples e de ciclo duplo. A aprendizagem de ciclo simples e de ciclo duplo representa uma mudança no comportamento organizacional resultante de mudança cognitiva do grupo que reconhece uma maneira melhor de atingir objetivos organizacionais. No primeiro nível, (ciclo simples) as práticas mudam, mas as normas internas permanecem inalteradas. No segundo nível, mais difícil de ocorrer, as normas e padrões de referência da organização também se alteram, atingindo um nível de efetividade e conhecimento organizacional mais alto. Assim, enfatizaram a detecção de erros e sua correção como componentes centrais da aprendizagem oriunda da prática reflexiva, introduzindo novas abordagens conceituais para além da simples solução de problemas.

Argyris e Schön (1978) definem a aprendizagem organizacional como o processo individual e coletivo de investigação (identificação e análise) pelo qual as teorias em uso organizacionais são construídas e modificadas. Nesse sentido, a aprendizagem individual se torna aprendizagem organizacional à medida que se incorpora às teorias em uso na organização. Ou seja, o processo cotidiano de detecção de erro e correção das atividades é individual e coletivo e é capaz de levar a mudanças nas ações (ciclo simples) ou nas estruturas do conhecimento organizacional (ciclo duplo), conforme representação contida no diagrama reproduzido dos autores na Figura 1 adiante. Em outras palavras, a diferença está na retroalimentação da aprendizagem: no ciclo simples corrige-se o erro detectado e adota-se prática mais efetiva; já no ciclo duplo, a aprendizagem com esse processo de detecção e correção leva à redefinição de padrões internos, de normas de operação e, consequentemente, dos níveis de produtividade, alterando os sistemas de referência organizacional.

Figura 1

Aprendizagem em circuito simples e duplo

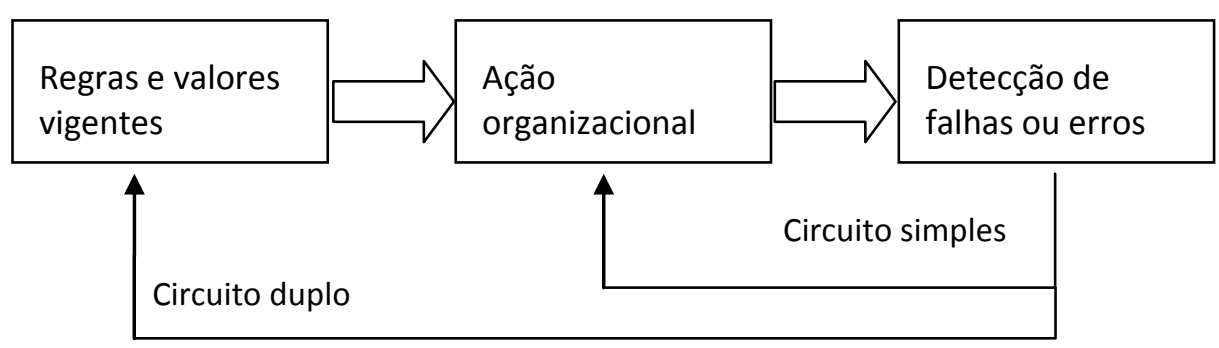

Fonte: baseado em Argyris e Schön (1978).

Daft e Weick (1984) propuseram uma visão da organização como sistemas de interpretação e estavam particularmente interessados em como as organizações interpretam o ambiente. Nessa visão, a interpretação é entendida como o processo organizacional no qual seus membros explicam o que é feito, descrevem o que aprenderam e solucionam problemas para decidir como continuar fazendo. Em outras palavras, os autores definem interpretação organizacional como o processo de traduzir eventos e desenvolver conhecimento compartilhado e mapas conceituais entre os membros da administração superior. Portanto, a interpretação 
organizacional precede a aprendizagem. Para Daft e Weick (1984), os indivíduos vêm e vão, mas as organizações preservam conhecimento, comportamentos, mapas mentais, normas e valores por muito tempo. A característica que distingue o conceito de interpretação é o compartilhamento; seja de valores, de informações, de percepções ou de soluções inovadoras. Levitt e March (1988) corroboraram essa posição afirmando que as organizações codificam, armazenam, retêm e transferem lições de sua história, independente da rotatividade de pessoal e da passagem do tempo. A Figura 2 representa de modo esquemático as relações entre o rastreamento (a obtenção de informações do ambiente), a interpretação (como processo de filtragem das informações e de dar sentido aos dados) e a aprendizagem nas organizações (representada pela tomada de ação e aplicação do conhecimento processado).

Figura 2

Diagrama esquemático das relações entre rastreamento, interpretação e aprendizagem nas organizações

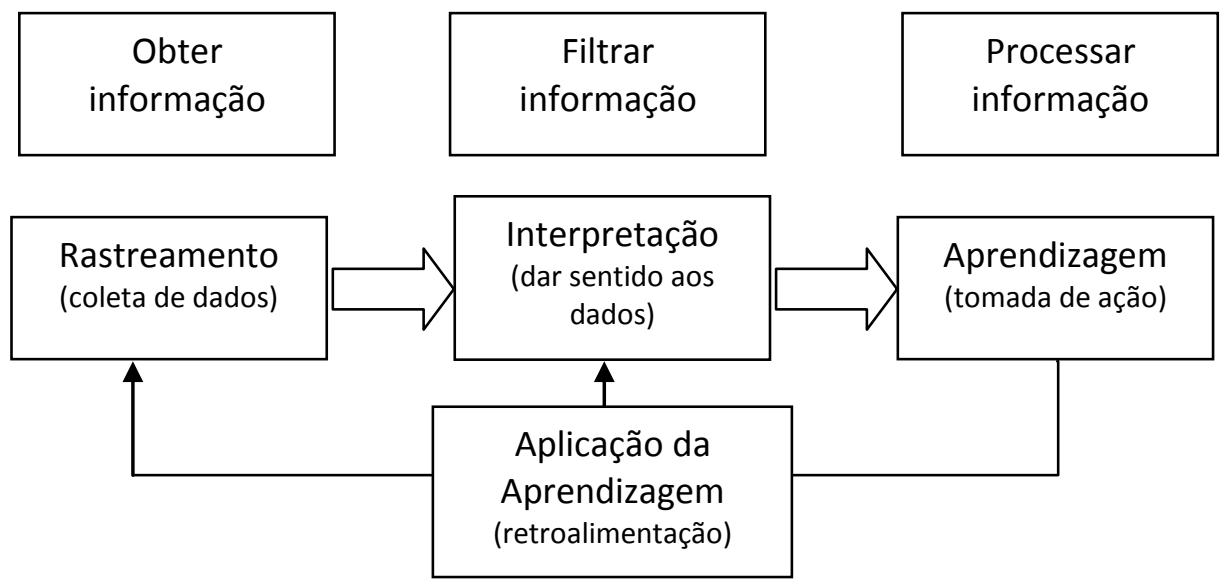

Fonte: Adaptada de Daft e Weick (1984, p. 286, tradução nossa).

Fiol e Lyles (1985), por seu turno, definiram a aprendizagem organizacional como o desenvolvimento de ideias, conhecimento e associações entre ações passadas, a efetividade dessas ações e ações futuras. Ao contrário dos indivíduos, as organizações desenvolvem e mantêm sistemas de aprendizagem que não apenas influenciam seus membros, mas, também, transferem-se no tempo pelas normas e histórias organizacionais. Fiol e Lyles (1985) também entendem o processo de aprendizagem como mudança, tanto comportamental quanto cognitiva. Entretanto, discordam de teóricos quanto a envolver principalmente mudança comportamental ou mudança cognitiva, ou ambas. Mudança comportamental envolve respostas reais, estruturas ou ações. Mudança cognitiva, por outro lado, envolve novos compartilhamentos de compreensão entre indivíduos da organização. Baseado nesse debate, os autores propuseram uma distinção entre adaptação organizacional e aprendizagem organizacional. O primeiro refere-se à mudança comportamental separada da mudança cognitiva, ou seja, a habilidade de fazer ajustes incrementais como resultado de uma adequação ao ambiente, aos objetivos e às políticas. Esse conceito seria similar ao conceito de aprendizagem de ciclo simples de Argyris e Schön (1978). O segundo, a aprendizagem organizacional propriamente dita, envolve não apenas a mudança comportamental, mas, também, as mudanças cognitivas (novas ideias, entendimentos ou mapas cognitivos). Essencialmente, novas associações entre a efetividade das ações do passado e decisões acerca das ações futuras. Esse conceito está associado ao alto nível de aprendizagem e à aprendizagem de ciclo duplo (ARGYRIS e SCHÖN, 1978).

Outra fonte muito referenciada acerca de aprendizagem organizacional baseia-se no estudo de Levitt e March (1988). A organização é encarada como um aprendizado codificado por inferências históricas transformadas em rotinas que orientam o comportamento. Portanto, a aprendizagem organizacional abordada sob o ponto de vista da dependência de trajetória histórica, cotidianamente acumulada na rotina com base na orientação objetiva da organização (resultados). Para Levitt e March (1988), a transferência de nível de aprendizagem, do individual para o organizacional, ocorre quando se modifica, cria ou altera rotinas organizacionais. Em 
resumo, a aprendizagem organizacional é baseada na rotina, possui dependência histórica e é orientada a resultados, objetivos. A memória organizacional seria, assim, o modo como as organizações preservam informações e ideias úteis acumuladas de experiências passadas. Portanto, esses pesquisadores subestimam processos de interpretação e análise enfatizados pelos demais teóricos. A interpretação organizacional representa uma tarefa desafiadora diante de julgamentos difíceis de relações de causa e efeito em bases limitadas de informação em torno de sistemas altamente complexos. Falsas interpretações ou relações causais espúrias tomadas com convicção por membros da organização são fenômenos que os autores designaram "aprendizagem supersticiosa". O sucesso empresarial pode ser afetado por uma falsa percepção de correlação entre ações e resultados que, de fato, foram obtidos por meio de outras circunstâncias favoráveis. Essas circunstâncias levam a equipe dirigente a cair no que chamaram de "armadilha de competência" (LEVITT e MARCH, 1988).

Em suma, resta aos pesquisadores o desafio da contribuição para o desenvolvimento de uma teoria da aprendizagem organizacional, partindo desses fundamentos teóricos historicamente construídos. Um bom caminho foi apontado por Oswick, Fleming e Hanlon (2011). Analisando a construção teórica no campo organizacional, esses autores identificaram um padrão dominante de empréstimos de outras disciplinas e propuseram uma construção teórica contrabalançada por um processo de mesclagem conceitual de mão dupla, envolvendo pensamento dissonante, sem analogias e com raciocínio contrafactual, para o desenvolvimento de teorias organizacionais novas e radicais (OSWICK, FLEMING e HANLON, 2011).

\section{Desafio da Análise Multinível}

Em regra, as teorias de aprendizagem possuem foco no indivíduo e realizam pesquisas no nível micro de análise. Por outro lado, os teóricos em aprendizagem organizacional reconhecem que grandes grupos de indivíduos são capazes de resolver problemas conjuntamente e de aprender a organizar o trabalho produtivo (RUSS-EFT, 2004). Assim, o nível de análise das pesquisas em aprendizagem organizacional focam os grupos/equipes (meso) e as relações interorganizacionais (macro). Os níveis de análise mais comumente considerados para o estudo da aprendizagem organizacional são o individual, o coletivo, ou de grupo, o organizacional e o interorganizacional (CAIRNS, 2011).

Assim, a aprendizagem organizacional é multinível, no sentido de que o fenômeno depende do aprendizado constatado nos níveis de indivíduo, grupo e organizacional e interorganizacional. Considera-se esta uma das premissas básicas da aprendizagem organizacional. Ao mesmo tempo, um grande desafio para pesquisadores, no sentido de viabilizar a medição do construto em quatro níveis diferentes. Uma visão mais simplista do fenômeno vem de Simon (1991), que considera que todo aprendizado ocorre na mente dos indivíduos e que uma organização aprende somente de duas maneiras: pelo aprendizado de seus membros ou pela inclusão de novos membros com conhecimentos que a organização não possuía. A dimensão intraorganizacional serve como base para a compreensão da dimensão interorganizacional, ao considerar o foco de análise na intersecção organização-ambiente (MOZZATO e BITENCOURT, 2013). Mais recentemente, o foco dos estudos da aprendizagem organizacional foi avançando do nível organizacional para os níveis multi e interorganizacional (MOZZATO e BITENCOURT, 2013).

Por outro lado, aprendizagem pode ser considerada como um fenômeno interpessoal (ANTONELLO e GODOY, 2011). Embora o indivíduo seja o agente do processo e sujeito do ato de aprender, o conteúdo e o contexto da aprendizagem referem-se ao ambiente coletivo, social. No âmbito das organizações, a gestão do conteúdo de aprendizagem, a acumulação de informações e conhecimento adquirido da experiência e da evolução tecnológica e o processo de utilização e transferência interna desse conhecimento são os mecanismos que explicam como grupos e organizações aprendem.

Portanto, a aprendizagem organizacional se apresenta como um fenômeno multinível, que exige abordagens multidisciplinares e multiníveis para o seu estudo. Para tanto, a pesquisa nas organizações deve considerar a 
noção de níveis cruzados de inferências do fenômeno. A devida separação da aprendizagem individual dos referidos mecanismos de aprendizagem organizacional pode ser possível por abordagem multinível alternativa; no detalhamento dos fundamentos teóricos, do construto pesquisado e da efetiva medição do fenômeno (voltaremos aos desafios metodológicos adiante). Cangelosi e Dill (1965) recomendavam que os estudos do campo focassem a interação entre a aprendizagem individual e organizacional.

Tendo em vista o desafio teórico desse campo, cabe descrever alguns dos quadros de análise teóricos (theoretical frameworks) utilizados para estudar a aprendizagem organizacional, com abordagem multinível.

O modelo de análise representado na Figura 3 procura abordar o fenômeno da aprendizagem organizacional de modo analítico, partindo do pressuposto de que se trata de um processo que ocorre ao longo do tempo (ARGOTE e MIRON-SPEKTOR, 2011), em um ciclo influenciado permanentemente pelo contexto (organizacional e ambiental). Em resumo, o modelo propõe que a experiência interage constantemente com o contexto para criar conhecimento, em um processo cumulativo e mutuamente interativo entre organização e ambiente. Assim, o contexto afeta a experiência adquirida pela organização (ARGOTE e MIRONSPEKTOR, 2011). Por contexto organizacional entendem-se as características da organização, inclusive estrutura, cultura, tecnologia, identidade, memória, objetivos, incentivos e estratégia. O contexto ambiental também inclui os relacionamentos com outras organizações por alianças, joint ventures e participação em associações. Nesse modelo, o nível individual está representado pelo contexto ativo. Os membros da organização também são repositórios de conhecimento, experiência e capacidade de transferência.

Figura 3

\section{Modelo de análise teórica de aprendizagem organizacional}

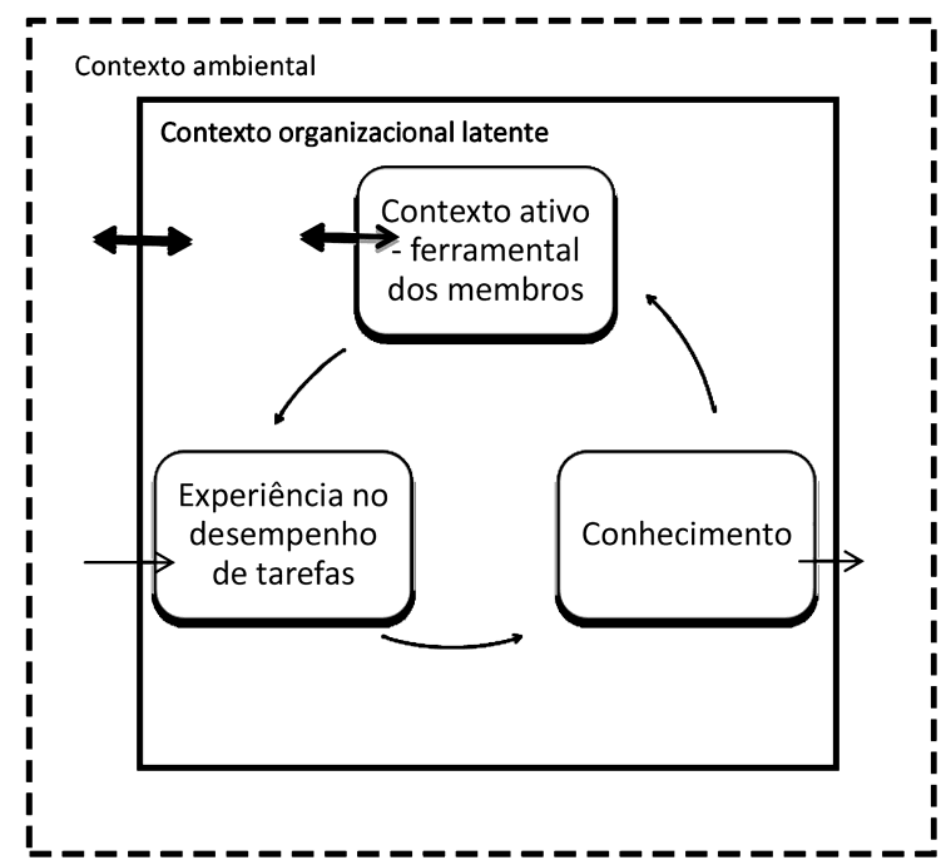

Fonte: Argote e Miron-Spektor (2011, p. 1125, tradução nossa).

O contexto latente organizacional afeta o contexto ativo. Por exemplo, compartilhamento de identidade, confiança mútua e segurança psicológica têm sido descritos como elementos do contexto que promovem a aprendizagem organizacional, à medida que facilitam a transferência de conhecimento no contexto ativo.

Em 1999, Crossan, Lane e White propuseram um modelo de análise teórico de aprendizagem organizacional que contempla os níveis de análise individual, grupo e organizacional. Ademais, identificaram como esses 
níveis de aprendizagem se conectam por meio de quatro processos que ajudam a explicar como a aprendizagem desenvolve: intuição, interpretação, integração e institucionalização (4 Is).

A intuição é o processo consciente de reconhecimento de padrões ou possibilidades a partir da experiência pessoal. Portanto, ocorre exclusivamente em nível individual. A interpretação é o processo de verbalização de intuições mentais do indivíduo. As pessoas desenvolvem linguagem e, muitas vezes, metáforas, para poder explicar as intuições para os outros. A integração é o processo de desenvolvimento compartilhado de sentido entre indivíduos para ação coletiva coordenada. Trata-se do processo que conecta o grupo ao nível organizacional. O diálogo se mostra vital nesse processo. Por sua vez, a institucionalização é o processo de incorporação da aprendizagem do indivíduo ou do grupo na organização. Isso ocorre geralmente por meio de normas, manuais, rotinas ou estruturas adotadas no nível organizacional (CROSSAN, LANE e WHITE, 1999).

À medida que a aprendizagem vai do nível individual para o nível organizacional, ela se torna mais fluida, mais incremental e mais dissociada. Isso ocorre porque a institucionalização do conhecimento aprendido requer um período de questionamento, amadurecimento e deliberação de membros organizacionais influentes. Como resultado, processos de institucionalização são mais raros que os demais, como a intuição. Por outro lado, a aprendizagem institucionalizada tende a perdurar à medida que as pessoas buscam garantir que os procedimentos formais e as normas sejam seguidas (CROSSAN, LANE e WHITE, 1999). Esses quatro processos de aprendizagem são particularmente úteis para entender os insights intuitivos que ocorrem na organização e as inovações organizacionais decorrentes desse processo individual quando compartilhado com o grupo. Esses quatro processos nos três níveis se conectam por alimentação e retroalimentação, na interação dos indivíduos nos sentidos botton-up e top-down (cf. diagrama apresentado na Figura 4).

Entretanto, um modelo de análise de aprendizagem organizacional desprovido do componente político dentro da dinâmica organizacional deve ser considerado incompleto (LAWRENCE, MAUWS, DYCK et al., 2005). Os componentes de poder e política remanescem ignorados entre os pesquisadores do campo e, segundo Lawrence, Mauws, Dyck et al. (2005), prejudicam o desenvolvimento completo da teoria de aprendizagem organizacional. Partindo dessa constatação, os autores propõem a inclusão do poder no modelo de análise 4 Is (intuição, interpretação, integração e institucionalização), conforme o diagrama da Figura 4, que expõe o movimento crosslevel da política da aprendizagem (baseado em modelo proposto por CROSSAN, LANE e WHITE, 1999). 
Figura 4

\section{Processos sociais, psicológicos e políticos de aprendizagem organizacional}
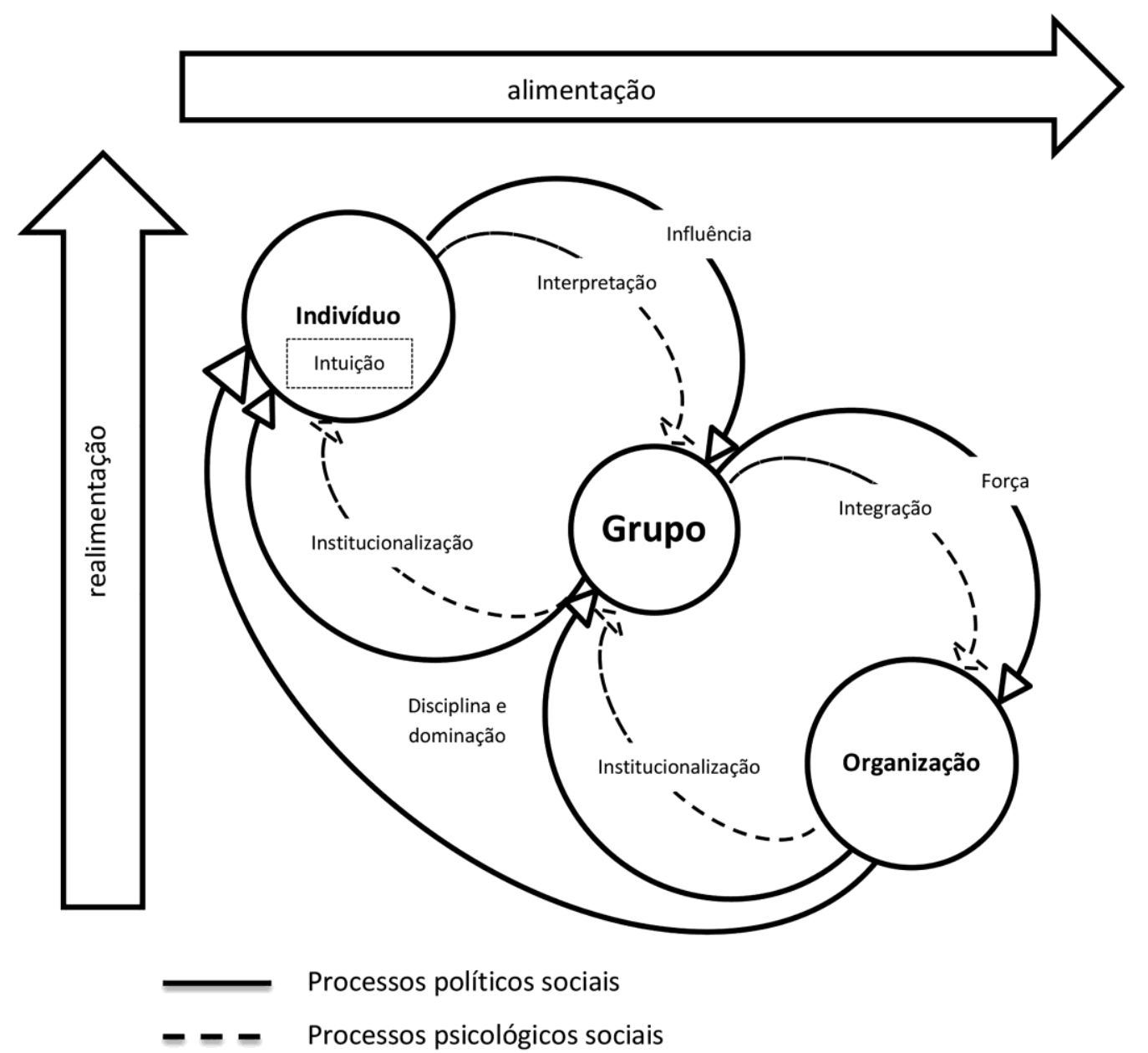

Fonte: Lawrence, Mauws, Dyck et al. (2005, p. 183, tradução nossa).

Esse componente do poder e da política nos estudos de aprendizagem organizacional tem sido negligenciado pelos pesquisadores. Teóricos críticos apontam o fenômeno como elemento de dominação no espaço social organizacional e reconhecem a relevância para os estudos críticos o enriquecimento da base de conhecimento, a melhoria do processo de decisão e os aumentos na "aprendizagem" e na adaptação (ALVESSON e DEETZ, 1999). Pesquisas pós-modernas e críticas podem embasar-se na: 1) relação poder/conhecimento que surge sob a perspectiva de Nietzsche; 2) experiência e linguagem surgida com o estruturalismo linguístico; 3) teoria do conflito social baseada em Marx; e 3) na complexidade do sujeito humano, que vem de Freud (ALVESSON e DEETZ, 1999). Essa relação aprendizagem e política também é tratada por Habermas (1984 apud ALVESSON e DEETZ, 1999), que separa dois processos históricos de aprendizagem e formas de racionalidade: o tecnológico-científico-estratégico, associado ao mundo do sistema; e o comunicativo-político-ético, associado ao mundo vivido.

Para Weber (2004), administração burocrática significa dominação em virtude de conhecimento e o nível de conhecimento e habilidade para assumir funções superiores na organização é verificado por provas e certificações. Assim, a visão da aprendizagem weberiana representa "formidável poder devido ao conhecimento profissional" e, assim, a burocracia possui tendência de fortalecer-se mais pelo saber prático do serviço, ou seja, o conhecimento da execução das tarefas e dos documentos e manuais, que representa a aprendizagem organizacional institucionalizada. Revisão de literatura a partir dos paradigmas definidos por 
Burrel e Morgan (2001), em diálogo com as classificações de Alvesson e Deetz (1999) e explorando abordagens alternativas propostas pela teoria crítica, pelo pós-modernismo e pelo construcionismo social para desenvolver análises organizacionais, conclui que há um reconhecimento crescente da necessidade de visões mais dinâmicas, críticas, processuais e sociais para os estudos de aprendizagem organizacional (KARATAZ-ÖZKAN e MURPHY, 2010).

Portanto, para um fenômeno reconhecido como multinível e multifacetado, o desafio encontrado pelo pesquisador é planejar uma investigação do construto em diversas perspectivas, qualquer que seja o quadro de análise teórico escolhido. Crossan, Maurer e White (2011) enxergam grande potencial para o modelo 4 Is para enriquecer e fortalecer as perspectivas multiníveis, podendo resultar em uma teoria de aprendizagem organizacional. Mais ainda, esses autores acreditam que a matriz 2 × 2 de 4 paradigmas de Burrel e Morgan (2001) sublinha um problema-chave no desenvolvimento de uma teoria compreensível de aprendizagem organizacional. Cada um dos processos do modelo 4 Is possui pressuposições distintas sobre organizações e sociedades e operam por dentro e ultrapassam paradigmas diversos. Utilizar lentes diferentes para processos distintos pode vir a contribuir para o importante debate acerca da tensão entre exploration (intuição, inovação, sugestões de mudança etc.) e explotation (eficiência, padronização, institucionalização) (BRUSONI e ROSENKRANZ, 2014).

Intuição estabelece contradições, mudança, possibilidades e o potencial de enxergar e criar uma nova realidade, fora da lógica positivista e racional. A visão e o insight não se enquadram nos modelos mentais e nas normas e rotinas organizacionais. Intuição é um processo altamente subjetivo, mais próximo do paradigma humanista radical de Burrel e Morgan (2001). Por outro lado, interpretação manifesta-se como um processo de incorporação, em palavras e ações, da intuição individual. Ao se comunicar com o grupo, esse processo poderia estar sendo analisado com a lente do paradigma do quadrante interpretativista.

Por seu turno, a integração de uma nova ideia demanda que membros de um grupo dentro da organização tomem atitudes diferentes daquelas do passado organizacional para aprovar, aceitar e apoiar uma inovação. Integrar uma nova ideia requer, portanto, que os membros ignorem ou ultrapassem normas e rotinas estabelecidas da estrutura. Esse processo poderia ser mais bem compreendido, então, sob a perspectiva do quadrante do paradigma estruturalista radical, confrontando a realidade objetiva estabelecida na organização.

Caso a inovação persista, torna-se institucionalizada. Modificações nas normas, regras, rotinas e estruturas institucionalizam a mudança dentro da organização. Institucionalizar uma mudança requer que seja possível sua replicação. Ao ocorrer esse processo, torna-se mais observável, prevalente, objetivo, real, possibilitando uma abordagem positivista. Este último processo seria, então, observado sob a ótica do paradigma funcionalista de Burrel e Morgan (CROSSAN, MAURER e WHITE, 2011). A Figura 5 apresenta a associação entre o processo dos 4 Is e os paradigmas de Burrel e Morgan, valendo ressaltar que ele não se caracteriza como um processo cíclico. 
Figura 5

Processos 4 Is e sua relação com os paradigmas de Burrel e Morgan

SOCIOLOGIA DA MUDANÇA RADICAL

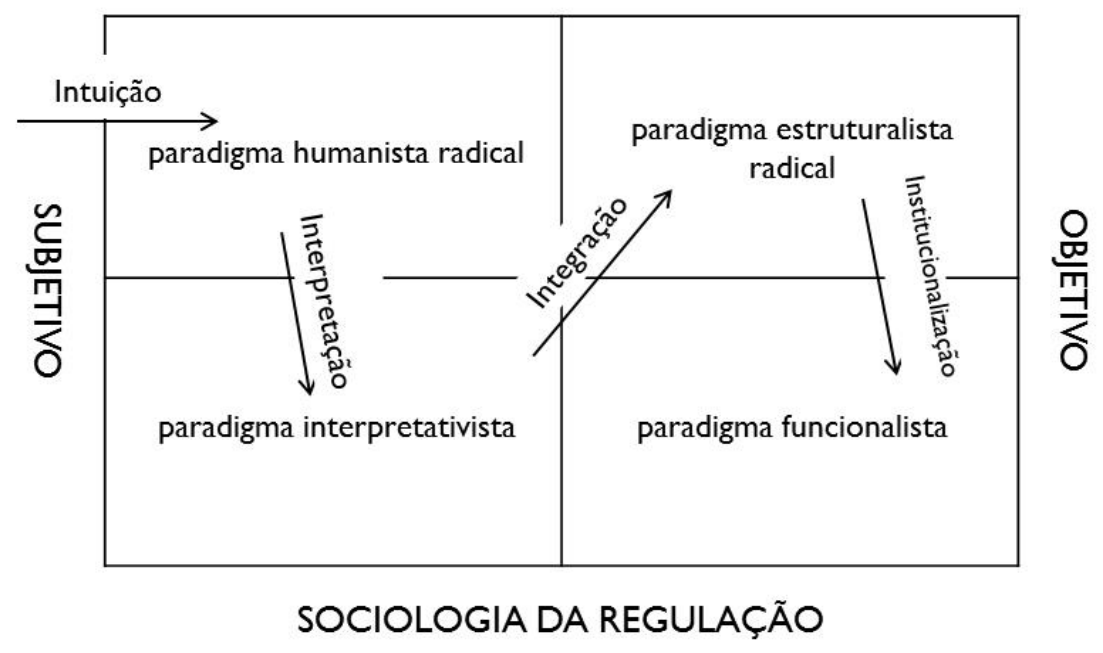

Fonte: Adaptada de Crossan, Maurer e White (2011, p. 456, tradução nossa).

Um modelo multifacetado e integrativo de aprendizagem organizacional foi proposto por Friedman e Popper (2002), com base nas pesquisas e teorias do campo, mapeando condições organizacionais (fatores e características) que proporcionam mais ou menos aprendizagem, como fatores estrutural, cultural, psicológico, político e contextual. O objetivo do modelo foi alcançar um balanceamento entre a simplicidade e a complexidade, sendo completo o suficiente para capturar os fatores influentes da aprendizagem organizacional e parcimonioso para ser facilmente utilizado e seguido (FRIEDMAN, LIPSHITZ e POPPER, 2005).

Portanto, apenas pelos exemplos apresentados, nota-se uma variedade de modelos de quadro de análise teóricos de aprendizagem organizacional. O desafio para o pesquisador é desenvolver projetos de pesquisa que investiguem os diversos níveis do fenômeno (individual, coletivo [grupo], organizacional e interorganizacional), dentro de um quadro de análise que contemple os fatores influentes na aprendizagem organizacional, como o fator político acrescentado por Lawrence, Mauws, Dyck et al. (2005), de modo multiparadigmático.

\section{Desafio da Interdisciplinaridade}

A aprendizagem organizacional é inerentemente um tema interdisciplinar e a pesquisa de aprendizado organizacional baseia-se e contribui para o desenvolvimento de uma variedade de campos, incluindo: comportamento organizacional, psicologia cognitiva e social, sociologia, economia, sistemas de informação, gestão estratégica, teoria organizacional, economia e engenharia (DODGSON, 1993; ARGOTE e MIRONSPECTOR, 2011). Mathieu e Chen (2011) recomendam abordagem multidisciplinar nas pesquisas organizacionais, superando a tensão em busca de identidade única com princípios próprios e aceitando a alternativa da diversidade e riqueza da exploração interdisciplinar.

Raízes da polissemia da aprendizagem organizacional são apontadas por Antonello e Godoy (2011) como parte da própria abrangência do tema, que envolve diversos campos teóricos: psicológico, sociológico, cultural, histórico e metodológico, além da gestão. Sob a perspectiva psicológica, aprendizagem individual serve de analogia para a aprendizagem organizacional ou é o elemento-chave para compreender o processo 
de aprendizagem organizacional. Por sua vez, a perspectiva sociológica encara a aprendizagem como inerente e integrada ao cotidiano dos indivíduos, envolvendo relações sociais e de influência baseadas no conhecimento, como socialização de códigos culturais específicos. Sob essa perspectiva, aprendizagem organizacional pode ser investigada como política de mobilização de recursos de poder e pode ser compreendida como uma das funções do sistema organizacional que engendram mudança em algumas ocasiões, mas conservam o status quo em outras. Em perspectiva antropológica, a aprendizagem organizacional faz referência à aprendizagem que o indivíduo realiza em contexto de estruturas sociais, com foco no coletivo, sua cultura e linguagem. Embora tenha atraído pouca atenção do campo, a perspectiva da ciência política sobre o tema o percebe como um processo político no qual os atores investem esforços para influenciar uns aos outros, interpretar a experiência e construir coalizões internas. Acrescentar o elemento de poder ao modelo 4 Is contribui para a compreensão do fenômeno sob a perspectiva da ciência política. A visão histórica, por seu turno, pode contribuir muito com os estudos de aprendizagem organizacional. A dependência da trajetória mostra que a forma como uma organização empregou a aprendizagem no passado pode ser utilizada no futuro e a história e identidade de uma organização é construída, em grande medida, sobre a aprendizagem coletiva de indivíduos e grupos no transcorrer do tempo, construindo linguagem, cultura e conhecimento compartilhado. Em perspectiva econômica, a aprendizagem organizacional se apresenta como instrumento de acréscimo no desempenho econômico, como ganhos de produtividade (ANTONELLO e GODOY, 2011). O uso da curva de aprendizagem como instrumento econométrico possui essa visão econômica de redução de horas de trabalho por produto (ARGOTE, 2013).

Hager (2011) demonstra influências diversas nas teorias de aprendizagem no trabalho. Entre elas, as teorias socioculturais, fortemente influenciadas pela sociologia e antropologia, que rejeitam os principais pressupostos da influência psicológica desse campo e questionam a natureza da aprendizagem profissional contínua (HAGER, 2011). Portanto, buscar influências teóricas distintas exige do pesquisador lidar com contradições, divergências e dialéticas próprias do ponto de vista de cada campo do conhecimento. Dodgson (1993) já apontava a necessária abordagem multidisciplinar em busca de uma compreensão mais completa que a complexidade do fenômeno requer.

\section{Desafio Conceitual}

O desafio conceitual se apresenta como um problema na pesquisa do tema considerando a multiplicidade de conceitos teóricos, que dificulta definir o construto científico e suas fronteiras conceituais, de modo a restringir o escopo de pesquisa e possibilitar a construção de método de mensuração do fenômeno nas organizações. Ao mesmo tempo, o conceito é utilizado frequentemente com sentido metafórico e por analogia com aprendizagem no nível individual (MARCH, 1991). Todo pesquisador deve buscar uma definição operacional a ser utilizada em pesquisa de aprendizagem organizacional que faça distinções conceituais claras. A partir disso, o desafio metodológico se restringe a construir indicadores que possam servir para observar e mensurar o grau de aprendizagem em organizações.

A natureza multifacetada do conceito de aprendizagem favorece o advento das diversas definições associadas a ele (COELHO JUNIOR e BORGES-ANDRADE, 2008). A noção de aprendizagem organizacional referese ao processo pelo qual a aquisição de conhecimentos e de entendimentos sobre a realidade possibilita uma melhoria da ação organizacional (FIOL e LYLES, 1985). Uma discussão articulada a respeito dos conceitos de conhecimento, aprendizagem e inovação organizacional, apresentada por Isidro-Filho e Guimarães (2010), leva em conta o mapa teórico de como conhecimento, aprendizagem e inovação em organizações se relacionam. O diagrama da Figura 6 ilustra essa articulação conceitual e o desafio de distinguir construtos fortemente relacionados.

Da mesma forma, os temas competência e aprendizagem em organizações, apesar de bastante estudados nas décadas mais recentes, ainda se caracterizam por divergências conceituais e pelo modo de abordagem dos fenômenos (ODELIUS e SENA, 2009). Nesse cenário, falta consenso nos significados de aprendizagem organizacional e falta uniformidade nos conceitos utilizados, originando o desenvolvimento de inúmeros 
modelos, dificultando integração e consolidação de conhecimentos sobre o fenômeno (ARGOTE, 2005; FRIEDMAN, LIPSHITZ e POPPER, 2005; ODELIUS e SENA, 2009). Huber (1991) encontrou lacunas na literatura e apresentou processos e subprocessos associados à aprendizagem organizacional, ampliando os construtos envolvidos no fenômeno.

Outro conceito correlato tem atraído grande atenção de muitas publicações desde o artigo seminal de Teece, Pisano e Shuen (1997) sobre capacidades dinâmicas, gerando uma vasta agenda de investigação (BARRETO, 2010). O tema está diretamente relacionado ao conceito de vantagem competitiva, relativa a recursos e competências baseadas nas idiossincrasias das firmas, difíceis de ser imitadas. Andrews (1987 apud TEECE, PISANO e SHUEN, 1997) define competência distintiva como algo que a organização faz muito bem feito. Trata-se, aqui, de capacidades que organizações demonstram em realizar, produzir e inovar de modo específico e capaz de garantir vantagem em relação aos demais concorrentes do mercado. Embora o conceito de capacidades dinâmicas possua vínculo com a perspectiva da visão baseada em recursos (RBV), cujas ideias principais surgem a partir dos estudos de Edith Penrose, capacidades dinâmicas vão muito além da simples ampliação do sentido da RBV, uma vez que se referem ao poder de manipular os recursos e extrair deles maior proveito e retorno à organização (ZOTT, 2003).

Barreto (2010) enfrenta o desafio imposto pelo crescimento da literatura sobre o tema com sucessivas e distintas definições do construto, sujeitas a relevantes críticas e disparando agendas de pesquisa em direções diversas. Essa proliferação de conceitos demonstra o interesse despertado no tema, ainda considerado incipiente. Assim, considera-se que a consolidação do conceito de capacidades dinâmicas seja requisito necessário para o avanço das pesquisas (BARRETO, 2010).

Figura 6

Interfaces e limites entre conhecimento, aprendizagem e inovação em organização

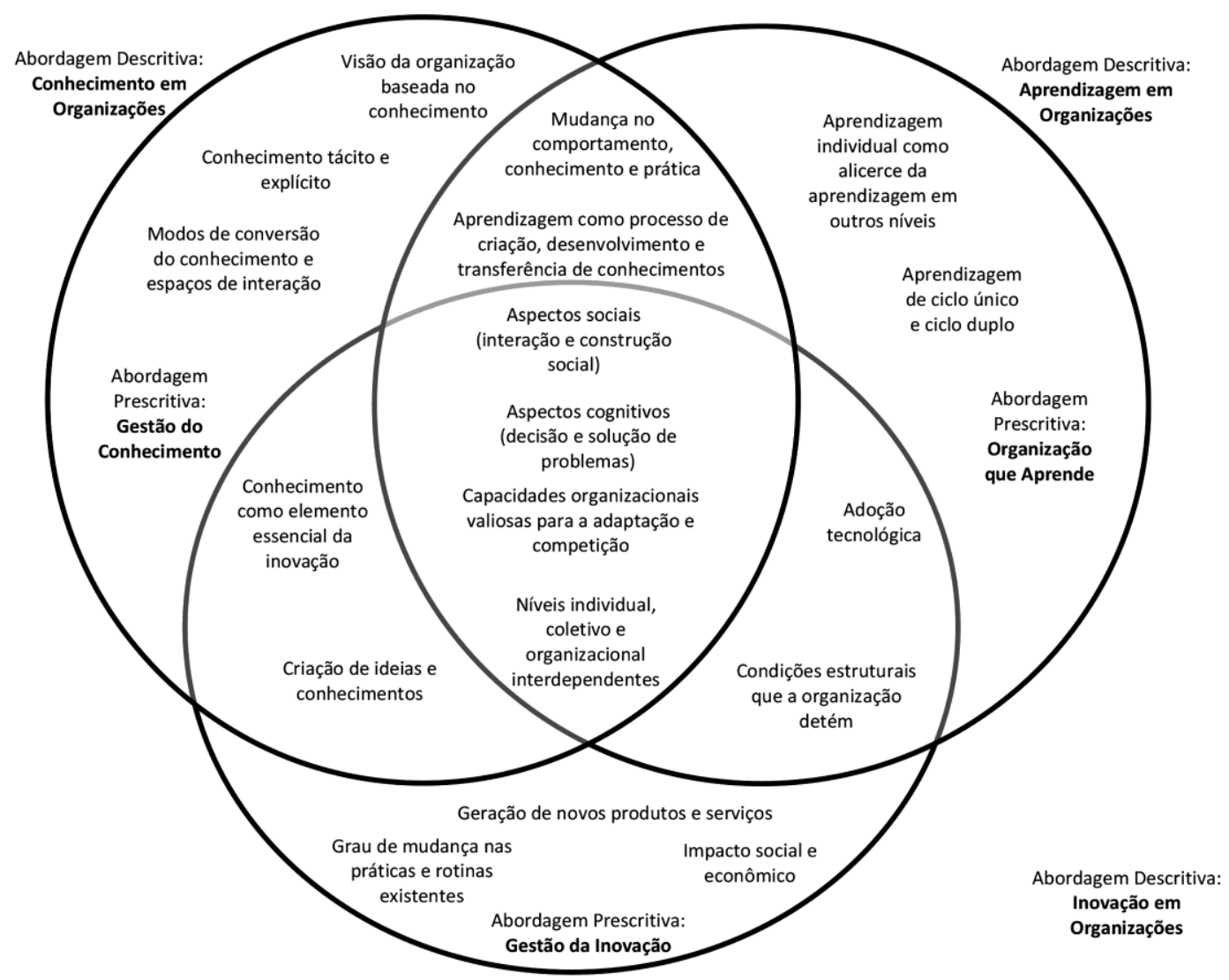

Fonte: Isidro-Filho e Guimarães (2010, p. 137). 
Zollo e Winter (2002) propõem uma vinculação relevante entre aprendizagem organizacional e desenvolvimento de capacidades dinâmicas. O diagrama da Figura 7 relaciona os mecanismos de aprendizagem a capacidades dinâmicas, resultando em evolução das rotinas operacionais capazes de garantir vantagens competitivas. Assim, capacidades dinâmicas, conhecimento, aprendizagem e inovação são constructos inter-relacionados em uma organização, comumente caracterizados como polissêmicos e de difícil integração.

\section{Figura 7}

\section{Aprendizagem, capacidades dinâmicas e rotina operacional}

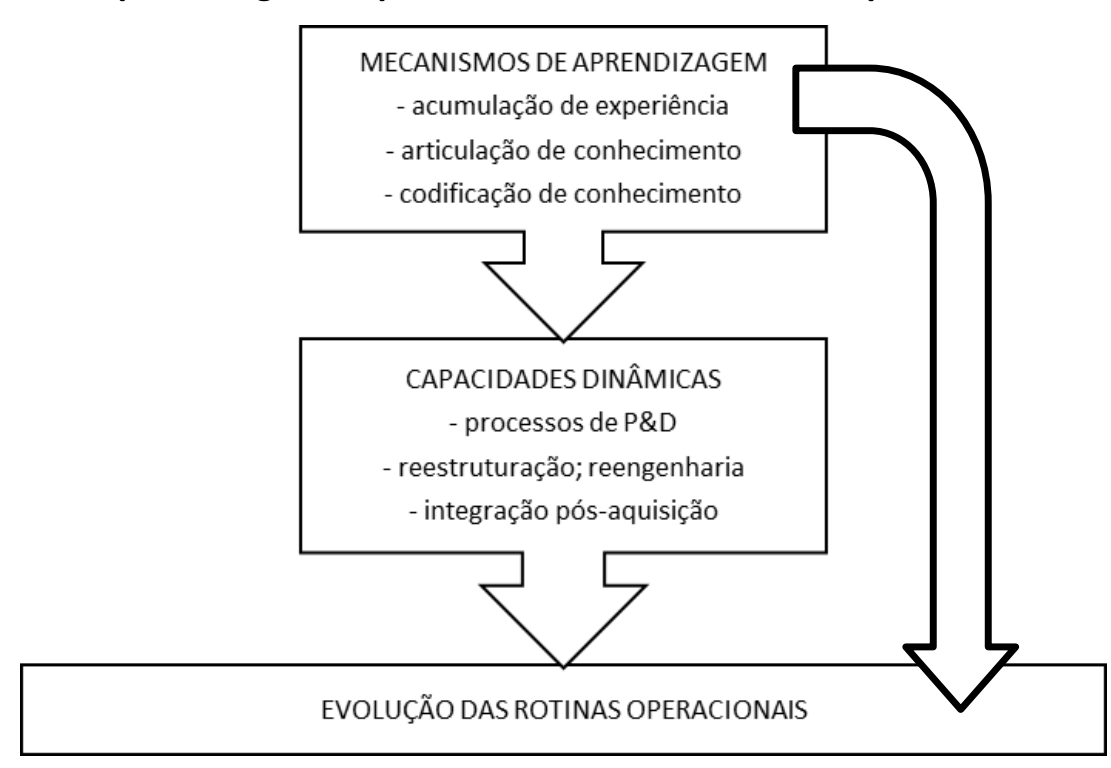

Fonte: Zollo e Winter (2002, p. 340, tradução nossa).

Portanto, capacidades dinâmicas se confundem com mecanismos organizacionais de adaptação ao ambiente por meio de alterações de rotinas e reconfiguração de recursos. Isso envolve: 1) acumulação de experiência; 2) articulação do conhecimento; e 3) processos de codificação de conhecimento em ambiente dinâmico, propiciando rotinas definidas voltadas ao desenvolvimento e à adaptação da rotina operacional (ZOLLO e WINTER, 2002).

Outro conceito correlato, aprendizagem tecnológica é entendida como um processo que permite à empresa acumular competências tecnológicas ao longo do tempo (FIGUEIREDO, 2009). Nesse sentido, as características-chave dos processos de aprendizagem definidas por Figueiredo (2009) são: variedade, intensidade, funcionamento, e interação. Os processos de aprendizagem apontados para empresas de industrialização foram: i) processos de aquisição externa de conhecimento; ii) processos de aquisição interna de conhecimento; iii) processos de socialização de conhecimento; e iv) processos de codificação de conhecimento. Os processos iii e iv se mostraram críticos para a conversão da aprendizagem individual para a organizacional naquela pesquisa.

Nessa linha, Ellström (2011) propõe um quadro de análise para aprendizagem informal no trabalho e o potencial de aprendizagem no ambiente de trabalho, partindo de uma definição de aprendizagem organizacional como mudanças no conhecimento e nas práticas organizacionais que são mediadas pelo aprendizado individual e a criação de conhecimento. O potencial de aprendizagem no ambiente de trabalho resulta de relações complexas entre fatores, incluindo: a) características das atividades, como complexidade, variedade e controle; b) oportunidades para avaliação, reflexão e retroalimentação; c) tipo e grau de formalização dos processos de trabalho; d) arranjo organizacional para a participação dos trabalhadores na solução de problemas e planejamento das atividades produtivas; e e) fontes de aprendizagem, em termo de tempo de análise, interação entre membros e reflexão, por exemplo (ELLSTRÖM, 2011). Fuller e Unwin 
(2011) apresentam outras características favoráveis e restritivas dos locais de trabalho como ambientes de aprendizagem, como promoção ou restrição à participação em comunidades de prática.

Nesse sentido, características da organização vêm sendo pesquisadas diferenciando o fenômeno da aprendizagem organizacional das condições de suporte organizacional à aprendizagem. $\mathrm{O}$ que caracteriza uma organização que suporta a aprendizagem é a abertura para que os funcionários criem, adquiram e transfiram conhecimentos (GARVIN, 2000). Nessa linha do conceito de aprendizagem organizacional de Peter M. Senge (1998), em "The Fifth Discipline", Garvin, Edmondson e Gino (2008) entendem que uma "learning organization" se estrutura em três pilares. O primeiro é um ambiente que promova os processos de aprendizagem, ou seja, que valorize as diferenças de opiniões, que seja aberto a novas ideias, que garanta uma reserva de tempo para a reflexão sobre o trabalho realizado e que garanta a segurança psicológica aos funcionários. O segundo pilar está assentado nos processos e práticas de aprendizagem concretos. Nesse caso, baseia-se nas atividades que se realizam na prática para fomentar o aprendizado, como ações de educação e aprendizagem, trocas de informação, recolha de informação, experimentação e promoção de debates. O terceiro pilar é a capacidade da liderança de valorizar e promover a aprendizagem. Cada um desses pilares, e seus subcomponentes, são vitais para o conjunto, são independentes e podem ser medidos separadamente. Dessa forma, é possível avaliar a organização por várias dimensões que compõem o processo de aprendizagem organizacional (GARVIN, 2000). Embora os conceitos de aprendizagem organizacional e organização que aprende possuam algumas diferenças, ambos foram tratados na literatura como complementares e dizem respeito ao mesmo fenômeno da aprendizagem em organizações (VALASKI, MALUCELLI e REINEHR, 2012).

Portanto, nesse contexto teórico e conceitual cada vez mais diverso e complexo, Friedman, Lipshitz e Popper (2005) acreditam que a literatura acadêmica e popular de aprendizagem organizacional contribuiu para uma mistificação do conceito, de cinco maneiras: a) promovendo continuamente novas definições conceituais que incrementam a complexidade, com pouca contribuição para o esclarecimento conceitual; b) antropomorfizando o conceito de aprendizagem, tratando o fenômeno no nível organizacional da mesma forma que no nível individual; c) dividindo o campo entre os visionários e os céticos; d) pela reificação de terminologia atraente; e e) mistificando deliberadamente o conceito. Concluindo, pesquisadores desse campo se defrontam com o desafio de desmistificar o conceito de aprendizagem organizacional, bem como distingui-lo claramente de outros fenômenos e construtos teóricos similares.

\section{Desafio Metodológico}

Diante dessa multidimensionalidade do fenômeno, dos vários quadros de análise teóricos, dessa diversidade conceitual e da constatação que o processo de aprendizagem organizacional é multinível e deve ser abordado sob as perspectivas multidisciplinar e multiparadigmática, está dado o desafio metodológico para a pesquisa desse tema.

Alguns autores apontaram que, até recentemente, havia pouca pesquisa empírica sobre aprendizagem organizacional (ROUSSEAU, 1997). Entretanto, estudos organizacionais são, necessariamente, estudos empíricos, explorando atitudes, comportamentos, experiências, artefatos, sentimentos, fatos e números (STABLEIN, 2006), e a coleta de dados seguida de sua interpretação faz parte do processo básico de uma coerência teórico-metodológica na construção de projetos de pesquisa desse campo. Estudos empíricos tendem a possuir efeitos duradouros na compreensão teórica do fenômeno estudado.

Embora os pesquisadores possuam diversas possibilidades de instrumentos de pesquisa de aprendizagem organizacional, terão o desafio de definir o método de acordo com seus objetivos de pesquisa. Um arsenal de instrumentos de pesquisa encontra-se à disposição do pesquisador, como, por exemplo: a) o questionário das dimensões da organização que aprende, o "Dimensions of the Learning Organization Questionnaire" (DLOQ), proposto por Marsick e Watkins (2003); b) o questionário de escala de benchmark de aprendizagem organizacional para análise comparativa interorganizacional (GARVIN, EDMONDSON e 
GINO, 2008); c) o instrumento de pesquisa baseado nos sete fatores de escala de cultura de aprendizagem em organizações, distinguindo os fatores de desempenho organizacional dos fatores relacionados com a cultura de aprendizagem em organizações, proposto por Menezes, Guimarães e Bido (2010) baseado no DLOQ; e d) escala proposta e utilizada por Templeton, Lewis e Snyder (2002) para mensuração da aprendizagem organizacional, traduzida em oito fatores.

O desenvolvimento do DLOQ tem contribuído para a pesquisa sobre o tema (SONG, CHERMACK e KIM, 2013). Guia para a aplicação desse instrumento foi publicado recentemente por Watkins e O’Neil (2013). Entretanto, alguns autores questionam a precisão dos métodos mais utilizados na pesquisa organizacional com base na autodeclaração individual em entrevistas ou respostas a questionários (DONALDSON e GRANT-VALLONE, 2002), sujeitas a viés de respostas motivadas pela desejabilidade social e propensão a "dar a resposta certa". O caráter das pesquisas baseadas exclusivamente em percepção individual tem sido um desafio do campo.

Os estudos com diários são também uma possibilidade metodológica a explorar no campo da aprendizagem organizacional. Zaccarelli e Godoy (2010) sugerem, em uma análise das perspectivas do uso do método dos diários nas pesquisas organizacionais, que importantes contribuições podem surgir para o entendimento dos processos de aprendizagem, de aprendizagem informal e pela experiência. Estudos com essa metodologia de análise dos registros cotidianos dos fatos e da interpretação individual podem vir a ser enriquecedores para o campo, além de ajudar a criar pontes multidisciplinares com outros campos do conhecimento, como a psicologia e a sociologia (ZACCARELLI e GODOY, 2010). Por seu turno,

De Souza Bispo e Godoy (2012) recomendam ver e compreender o fenômeno da aprendizagem sob as lentes da etnometodologia garfinkeliana, com um olhar diferenciado para a compreensão da aprendizagem organizacional a partir do conceito de prática. Buscar enxergar a aprendizagem organizacional sob os pressupostos da etnometodologia implica, para os autores, pensar esse fenômeno a partir das práticas cotidianas das organizações. Entretanto, a etnometodologia como possibilidade de investigação empírica para as pesquisas em Administração ainda carece de melhor sistematização como método qualitativo de pesquisa. Illeris (2011) sugere um modelo de análise de aprendizagem no trabalho simples e interessante, de difícil aplicação quantitativa, mas promissor em uma abordagem qualitativa. Nesse modelo, os processos básicos e as dimensões de aprendizagem correspondem ao conteúdo (conhecimento, compreensão e habilidades), aos incentivos (motivação, emoção e volição) e às interações (ação, comunicação e cooperação), no âmbito da sociedade (ILLERIS, 2011). Os dois primeiros processos ocorrem no nível individual, enquanto o terceiro ocorre no nível social envolto no ambiente sociocultural e no ambiente de aprendizagem técnico-organizacional.

Para pesquisas futuras de análise de aprendizagem no nível de grupo, Odelius, Abbad, Resende Junior et al. (2011) sugerem a triangulação de métodos e técnicas de coleta de dados, adotando medidas baseadas em percepções (questionários e entrevistas) e medidas objetivas, como indicadores de produção dos membros dos grupos (análises documentais) na comparação entre diferentes grupos quanto aos seus resultados, processos de aprendizagem e qualidade das interações sociais.

Assim, para enfrentar esse desafio metodológico, saídas adequadas devem ser construídas em torno de triangulação de métodos, de pesquisa empírica com análises qualitativas e quantitativas, bem como pelo uso de instrumentos de pesquisa menos ortodoxos, capazes de captar perspectivas inexploradas do fenômeno da aprendizagem organizacional. Em todos os casos, há necessidade de um modelo teórico-metodológico mais amplo que considere e integre os diferentes aspectos abordados em cada proposta. 


\section{Conclusão}

Nesse ensaio, a proposta foi destacar os desafios colocados para os pesquisadores do tema, com o objetivo de contribuir para as soluções de problemas no momento do planejamento de pesquisa em aprendizagem organizacional. Nesse sentido, foi possível identificar cinco desafios que merecem atenção e cuidado especial nos projetos de pesquisa.

Primeiro, o desafio teórico deve ser encarado como uma possibilidade de contribuição com o campo. A inexistência de uma teoria da aprendizagem organizacional prejudica um projeto de pesquisa, mas possibilita a exploração das fronteiras desse conhecimento, em busca de premissas gerais e aplicáveis a todas as organizações. Além disso, há necessidade de abordagens alternativas para a construção de uma teoria geral da aprendizagem capaz de conectar e atender a diversas áreas do conhecimento.

Segundo, como fenômeno complexo, a aprendizagem organizacional exige uma análise multinível. Nesse sentido, o desafio de pesquisa encontra-se na definição de um quadro de análise corretamente estruturado em níveis, mas consciente de que a aprendizagem é socialmente referenciada e, portanto, os limites dos níveis de análise não são nítidos. Para alcançar entendimento mais amplo, também se mostra essencial considerar o nível interorganizacional de aprendizagem (MOZZATO e BITENCOURT, 2014), uma vez que as organizações não atuam isoladamente e estão sempre atentas às suas similares.

O terceiro desafio posto para os estudos desse tema é construir pontes entre disciplinas que estudam e permeiam o campo. Os diversos pontos de vista e abordagens do mesmo fenômeno por ciências diferentes se apresentam ao mesmo tempo como um desafio e uma diversidade que pode contribuir com a compreensão plena do fenômeno. Entretanto, é necessário extrapolar limites e realizar leituras com jargões e bases teóricas distintas. Revisão de literatura realizada por Karataz-Özkan e Murphy (2010) aponta a importância de entender e aplicar paradigmas e perspectivas alternativas em pesquisa social sobre o fenômeno organizações, em geral, e sobre aprendizagem organizacional, em particular.

Quarto, o desafio conceitual deve ser considerado um processo de desmistificação do conceito e definição de construto teórico aplicável operacionalmente nos diversos níveis de análise. Vencer esse desafio depende dos pressupostos ontológicos e epistemológicos que são assumidos pelo pesquisador. As escolhas ontológicas e epistemológicas acerca da realidade desse campo variam e influem no processo de produção de conhecimento sobre aprendizagem organizacional.

Por fim, o quinto desafio, metodológico, refere-se a essa operacionalização do conceito, de modo prático, aplicável à pesquisa. $\mathrm{O}$ instrumental de pesquisa, qualitativa e quantitativa, é amplo. Entretanto, o caso concreto da aprendizagem organizacional impõe certos limites na aplicação de metodologias de pesquisa. Cabe, portanto, todo o cuidado necessário para a definição dos métodos e processos de investigação adequados para o sucesso de pesquisa nesse tema.

Assim, a contribuição almejada nesse artigo para pesquisas futuras foi destacar os desafios envolvidos na construção de conhecimento e teorias em aprendizagem organizacional, alertando para a necessidade de superar essas dificuldades por meio de projetos com arcabouço teórico-metodológico multidisciplinar, multiparadigmático e multinível, utilizando triangulação de teorias, métodos e técnicas de pesquisa.

\section{Referências}

ALVESSON, M.; DEETZ, S. Teoria crítica e abordagens pós-modernas para estudos organizacionais. In: CLEGG, S. et al. (Ed.). Handbook de estudos organizacionais. São Paulo: Atlas, 1999. v. 1, 227-266 p.

ANTONELLO, C. S.; GODOY, A. S. Aprendizagem organizacional no Brasil. Porto Alegre: Bookman, 2011. 
ARGOTE, L. Reflections on two views of managing learning and knowledge in organizations. Journal of Management Inquiry, v. 14, n. 1, p. 43-48, 2005.

ARGOTE, L. Organizational learning: creating, retaining and transferring knowledge. New York: Springer, 2013.

ARGOTE, L.; MCEVILY, B.; REAGANS, R. Introduction to the special issue on managing knowledge in organizations: creating, retaining, and transferring knowledge. Management Science, v. 49, n. 4, p. 5-8, 2003.

ARGOTE, L.; MCEVILY, B.; REAGANS, R. Managing knowledge in organizations: an integrative framework and review of emerging themes. Management Science, v. 49, n. 4, p. 571-582, 2003.

ARGOTE, L.; MIRON-SPEKTOR, E. Organizational learning: from experience to knowledge. Organization Science, v. 22, n. 5, p. 1123-1137, 2011.

ARGYRIS, C.; SCHÖN, D. A. Organizational learning: a theory of action perspective. Reading, Massachusetts: Addison-Wesley, 1978.

ARGYRIS, C.; SCHÖN, D. A. On organizational learning: theory, method, and practice. Reading, Massachusetts: Addison-Wesley, 1996. v. 2.

BARRETO, I. Dynamic capabilities: a review of past research and an agenda for the future. Journal of Management, v. 36, n. 1, p. 256-280, 2010.

BORGES-ANDRADE, J. E.; ABBAD, G. S.; MOURÃO, L. (Org.). Treinamento, desenvolvimento e educação em organizações e trabalho: fundamentos para a gestão de pessoas. Porto Alegre: Artmed, 2006.

BRUSONI, S.; ROSENKRANZ, N. A. Reading between the lines: learning as a process between organizational context and individuals' proclivities. European Management Journal, v. 32, n. 1, p. 147-154, 2014.

BURREL, G.; MORGAN, G. Sociological paradigms and organizational analysis. Aldershot: Ashgate, 2001.

CAIRNS, L. Learning in the workplace: communities of practice and beyond. In: MALLOCH, M. et al. (Eds.). The Sage handbook of workplace learning. London: Sage, 2011. p. 73-85 p.

CANGELOSI, V. E.; DILL, W. R. Organizational learning: observations toward a theory. Administrative Science Quarterly, v. 10, n. 2, p. 175-203, 1965.

CASTELLS, M. The rise of the network society: the information age - economy, society, and culture. Oxford: Wiley, 2011.

CHIVA, R.; ALEGRE, J. Organizational learning and organizational knowledge towards the integration of two approaches. Management Learning, v. 36, n. 1, p. 49-68, 2005.

COELHO JUNIOR, F. A.; BORGES-ANDRADE, J. E. Uso do conceito de aprendizagem em estudos relacionados ao trabalho e organizações. Paidéia, v. 18, n. 40, p. 221-234, 2008.

CROSSAN, M. M.; LANE, H. W.; WHITE, R. E. An organizational learning framework: from intuition to institution. Academy of Management Review, v. 24, n. 3, p. 522-537, 1999.

CROSSAN, M. M.; MAURER, C. C.; WHITE, R. E. Reflections on the 2009 AMR decade award: do we have a theory of organizational learning? Academy of Management Review, v. 36, n. 3, p. 446-460, 2011.

CYERT, R. M.; MARCH, J. G. A behavioral theory of the firm. Englewood Cliffs, NJ: Prentice-Hall, 1963. v. 2.

DAFT, R. L.; WEICK, K. E. Toward a model of organizations as interpretation systems. Academy of Management Review, v. 9, n. 2, p. 284-295, 1984.

DAVIS, G. F. Do theories of organizations progress? Organizational Research Methods, v. 13, n. 4, p. 690-709, 2010. 
DE SOUZA BISPO, M.; GODOY, A. S. A etnometodologia enquanto caminho teórico-metodológico para investigação da aprendizagem nas organizações. Revista de Administração Contemporânea, v. 16, n. 5, p. 684-704, 2012.

DODGSON, M. Organizational learning: a review of some literatures. Organization Studies, v. 14, n. 3, p. 375-394, 1993.

DONALDSON, S. I.; GRANT-VALLONE, E. J. Understanding self-report bias in organizational behavior research. Journal of Business and Psychology, v. 17, n. 2, p. 245-260, 2002.

ELLSTRÖM, P. Informal learning at work: conditions, processes and logics. In: MALLOCH, M. et al. (Eds.). The Sage handbook of workplace learning. London: Sage, 2011. 105-119 p.

FIGUEIREDO, P. N. Aprendizagem tecnológica e inovação industrial em economias emergentes: uma breve contribuição para o desenho e implementação de estudos empíricos e estratégias no Brasil. Revista Brasileira de Inovação, v. 3, n. 2, p. 323-361, 2009.

FIOL, C. M.; LYLES, M. A. Organizational learning. Academy of Management Review, v. 10, n. 4, p. 803-813, 1985.

FRIEDMAN, V. J.; LIPSHITZ, R.; POPPER, M. The mystification of organizational learning. Journal of Management Inquiry, v. 14, n. 1, p. 19-30, 2005.

FRIEDMAN, V. J.; POPPER, R. L. A multifacet model of organizational learning. Journal of Applied Behavioral Science, v. 38, n. 1, p. 78-98, 2002.

FULLER, A.; UNWIN, L. Workplace learning and the organization. In: MALLOCH, M. et al. (Eds.). The Sage handbook of workplace learning. London: Sage, 2011. 46-59 p.

GARVIN, D. A. Learning in action: a guide to putting the learning organization to work. Boston, MA: Harvard Business Press, 2000.

GARVIN, D. A.; EDMONDSON, A. C.; GINO, F. Is yours a learning organization? Harvard Business Review, v. 86, n. 3, p. 109-116, 2008

HAGER, P. Theories of workplace learning. In: MALLOCH, M. et al. (Eds.). The Sage handbook of workplace learning. London: Sage, 2011. 17-31 p.

HUBER, G. P. Organizational learning: the contributing processes and the literatures. Organization Science, v. 2, n. 1, p. 88-115, 1991.

ILLERIS, K. Workplaces and learning. In: MALLOCH, M. et al. (Eds.). The Sage handbook of workplace learning. London: Sage, 2011. 32-45 p.

ISIDRO-FILHO, A.; GUIMARÃES, T. A. Conhecimento, aprendizagem e inovação: uma proposta de articulação conceitual. Revista de Administração e Inovação, v. 7, n. 2, p. 127-149, 2010.

KARATAŞ-ÖZKAN, M.; MURPHY, W. D. Critical theorist, postmodernist and social constructionist paradigms in organizational analysis: a paradigmatic review of organizational learning literature. International Journal of Management Reviews, v. 12, n. 4, p. 453-465, 2010.

LAWRENCE, T. B. et al. The politics of organizational learning: integrating power into the 4I framework. Academy of Management Review, v. 30, n. 1, p. 180-191, 2005.

LEVITT, B.; MARCH, J. G. Organizational learning. Annual Review of Sociology, v. 14, p. 319-340, 1988.

MARCH, J. G. Exploration and exploitation in organizational learning. Organization Science, v. 2, n. 1, p. 71-87, 1991.

MARSICK, V. J.; WATKINS, K. E. Demonstrating the value of an organization's learning culture: the dimensions of the learning organization questionnaire. Advances in Developing Human Resources, v. 5, n. 2, p. 132-151, 2003. 
MATHIEU, J. E.; CHEN, G. The etiology of the multilevel paradigm in management research. Journal of Management, v. 37, n. 2, p. 610-641, 2011.

MENEZES, E. A. C.; GUIMARÃES, T. A.; BIDO, D. S. Dimensões da aprendizagem em organizações: validação do Dimensions of the Learning Organization Questionnaire (DLOQ) no contexto brasileiro. Revista de Administração Mackenzie, v. 12, n. 2, p. 4-29, 2010.

MOZZATO, A.; BITENCOURT, C. C. Understanding interorganizational learning through cooperation interorganizational relationships in different social spaces. 2013. Disponível em: <http://www.olkc2013.com/sites/www.olkc2013.com/files/downloads/179.pdf>. Acesso em: 31 out. 2014.

MOZZATO, A.; BITENCOURT, C. C. Understanding interorganizational learning based on social spaces and learning episodes. Brazilian Administration Review, v. 11, n. 3, p. 284-301, 2014.

ODELIUS, C. C.; SENA, A. C. Atuação em grupos de pesquisa: competências e processos de aprendizagem. Revista de Administração FACES Journal, v. 8, n. 4, p. 13-31, 2009.

ODELIUS, C. C. et al. Processos de aprendizagem, competências aprendidas, funcionamento, compartilhamento e armazenagem de conhecimentos em grupos de pesquisa. Cadernos EBAPE.BR, v. 9, n. 1, p. 198-219, 2011.

OSWICK, C.; FLEMING, P.; HANLON, G. From borrowing to blending: rethinking the processes of organizational theory building. Academy of Management Review, v. 36, n. 2, p. 318-337, 2011.

ROUSSEAU, D. M. Organizational behavior in the new organizational era. Annual Review of Psychology, v. 48, n. 1, p. 515-546, 1997.

RUSS-EFT, D. Toward a meta-theory of learning and performance. 2004. Disponível em: <http://0files.eric.ed.gov.opac.msmc.edu/fulltext/ED492309.pdf>. Acesso em: 31 out. 2014.

SENGE, P. As cinco disciplinas. HSM Management, v. 9, p. 82-88, 1998.

SIMON, H. A. Bounded rationality and organizational learning. Organization Science, v. 2, n. 1, p. 125-134, 1991.

SONG, J. H.; CHERMACK, T. J.; KIM, W. An analysis and synthesis of DLOQ-based learning organization research. Advances in Developing Human Resources, v. 15, n. 2, p. 222-239, 2013.

STABLEIN, R. 1.9 Data in Organization Studies. The SAGE Handbook of Organization Studies, 2006. 347 p.

TEECE, D. J.; PISANO, G.; SHUEN, A. Dynamic capabilities and strategic management. Strategic Management Journal, v. 18, n. 7, p. 509-533, 1997.

TEMPLETON, G. F.; LEWIS, B. R.; SNYDER, C. A. Development of a measure for the organizational learning construct. Journal of Management Information Systems, v. 19, n. 2, p. 175-218, 2002.

VALASKI, J.; MALUCELLI, A.; REINEHR, S. Ontologies application in organizational learning: a literature review. Expert Systems with Applications, v. 39, n. 8, p. 7555-7561, 2012.

WATKINS, K. E.; O’NEIL, J. The Dimensions of the Learning Organization Questionnaire (the DLOQ): a nontechnical manual. Advances in Developing Human Resources, v. 15, n. 2, p. 133-147, 2013.

WEBER, M. Economia e sociedade. Brasília, DF: Ed. UnB, 2004. v. 1.

ZACCARELLI, L. M.; GODOY, A. S. Perspectivas do uso de diários nas pesquisas em organizações. Cadernos EBAPE.BR, v. 8, n. 3, p. 550-563, 2010.

ZOLLO, M.; WINTER, S. G. Deliberate learning and the evolution of dynamic capabilities. Organization Science, v. 13, n. 3, p. 339-351, 2002.

ZOTT, C. Dynamic capabilities and the emergence of intraindustry differential firm performance: insights for a simulation study. Strategic Management Journal, v. 24, n. 2, p. 97-125, 2003. 